\title{
Factors influencing the sustained utilization of child welfare services among children 18 to 59 months in a low-income rural community.
}

\author{
Kennedy Diema Konlan ( $\sim$ dkkonlan@yahoo.com ) \\ Tamale Teaching Hospital \\ Roberta Mensima Amoah \\ University for Development Studies \\ Abdul Razak Doat \\ Tamale Nurses and Midwifery College \\ Milipaak Japiong \\ University of Health and Allied Sciences \\ Juliana Asibi Abdulai \\ Tamale Teaching Hospital
}

Research article

Keywords: Child, Welfare, Immunization, Growth monitoring, Childhood diseases

Posted Date: December 2nd, 2019

DOI: https://doi.org/10.21203/rs.2.17871/v1

License: (9) This work is licensed under a Creative Commons Attribution 4.0 International License.

Read Full License 


\section{Abstract}

ABSTRACT Background: Despite substantial progress in reducing child mortality, concerted efforts remain necessary to avoid preventable deaths in children under-5 years and to accelerate progress in improving child survival further. The patronage of child welfare services therefore remains paramount to the attainment of these goals. This study identified the factors that influence the patronage of child welfare services in a rural community in the Ho West District of the Volta region. Methodology: The study employed a quantitative descriptive cross-sectional design. Systematic sampling method was used to select 310 caregivers of children less than 60 months in the catchment area of the Abutia kloe sub district. Questionnaire was used to collect data from study respondents. The data was entered into a Microsoft Excel Spreadsheet and cleaned and subsequently exported to SPSS (version 22.0) for the data analysis. Data was analysed into simple descriptive statistics Results: The results showed that a significant number of respondents $(44.2 \%)$ had defaulted at a point during the continued growth monitoring process. The reasons for the default included children had completed major immunization (72.3\%), children had started school (57.4\%), and poor staff attitude (3.2\%). Noteworthy, It depicts that majority of mothers have an idea about the purpose of Growth chart (68\%). It is also worth noting that $86.5 \%$ of mothers are able to access a Child Welfare Clinic in less than thirty minutes. In addition, the results pointed out that there is a strong association between the level of caregivers' education and CWC attendance with a chi-square test of 3 and a P-value less than 0.05. Conclusion: Healthcare providers should intensify education on the need to continue growth monitoring up to 59 months even after the completion of major immunization. This goal can be attained if growth monitoring is incorporated into school health activities while policy implementers ensure the full implementation.

\section{Introduction}

The health and wellbeing of children under 59 months have been an issue of concern for decades and it is estimated that more than six million children still die before their fifth birthday each year (United Nations, 2017). Several interventions have been implemented as part of the Sustainable Development Goal three (SDG 3) to improve the health of individuals of all ages including children under five years of age and to reduce under-5 mortalities (Hák, Janoušková, \& Moldan, 2016). Despite substantial progress in reducing child mortality, concerted efforts remain necessary to avoid preventable under- 5 deaths in the coming years and to accelerate progress in improving child survival further. According to the WHO (2015), more than 10 million children under five die each year in developing countries due to preventable diseases and one in every nine Ghanaian children dies before reaching age five (GDHS, 2014). Some of the interventions currently in place to reduce under- 5 and child mortality includes the Expanded Programme for Immunization including micronutrient supplementation and the Integrated Management of Childhood and Neonatal Illness-IMCI (Ministry of Health, 2015; WHO, 2011). An increasing proportion of child deaths are in sub-Saharan Africa and Southern Asia and 4 out of every 5 deaths of children under age 5 occur in these regions (United Nations, 2017). This inequality in the health of children under-5 years has been attributed to weak healthcare systems in most of the African countries (UNICEF, 2016). This has 
energised most countries to implement primary healthcare interventions that encourages service provision in homes of beneficiaries.

As health care experts generally accept these interventions, it is also worth noting that it has some shortcomings. Home visits and community-based monitoring can improve coverage but practical benefits is dependent on the correct interpretation of growth charts, appropriateness of advice given, motivation given, resources of mothers to enable them take action, and the availability of oral rehydration salts, drugs, vaccines and other items needed in growth monitoring and promotion (Ashworth, Shrimpton \& Jamil 2008). A study conducted to assess the acceptability of community-based growth monitoring in a rural village in South Africa where growth monitoring is part of the Integrated Nutrition Programme showed that community-based delivery achieved $90 \%$ coverage and $64 \%$ of infants had at least five weighing in the first year (Phungula, Kvalsgig, \& Benadé, 2012). The study findings highlight the substantial contribution of community based interventions. Nonetheless, in Southern Ethiopia, the knowledge and attitude on growth monitoring and its associated factors among mothers/guardians of children less than two years revealed that only $36.9 \%$ of mothers thought growth monitoring is provided for children under five years while $31.8 \%$ of mothers did not know when the growth monitoring service is started. On growth chart, mothers identified it as a tool that shows the health status of the child (13.1\%), tool that shows developmental status of children (28.0\%), a certificate which is given for completing immunization (13.7\%) not know the definition of growth charts (45.2\%). In the same study, $56.5 \%$ of children have growth charts and among those who have growth charts $37.9 \%$ of them did not know what the curves mean (Beniam, Nardos, Ermias, Awol, \& Kamil, 2017) depicting the lack of appropriate understanding of the intricate activities during the monitoring process.

The awareness of mothers on what constitute growth monitoring is cardinal to their continual implementation of recommended services towards attaining improved health outcome for children less than five years. The awareness of immunization by mothers with children aged 18-59 months in Nigeria was good but most mothers do not know that most of the diseases in childhood could be prevented by immunization (Okafor, Dolapo, Onigbogi, \& lloabuchi, 2014). In a qualitative study at Atsib district in Northern Ethiopia to identify the practices and challenges of growth monitoring and promotion showed that, growth monitoring and promotion as a public health service for children did not resonate immediately to the mothers' minds unless the moderator raised the topic. All mothers used in the study were aware of immunization services, something that they also mentioned first when they were talking about public health services for children. However, mothers rarely mentioned growth monitoring and promotion as a separate weight-monitoring programme for their children; they often mentioned it as a part of other child health or maternal health services or in combination (Bilal, Moser, Blanco, Spigt, \& Dinant (2014). It is also imperative to note that socio-economic factors influence the mother's decision to seek child welfare services or otherwise. Mother's level of education, the total number of deliveries in a lifetime and mother's perception on birth attendants at home versus at health were found to be predictive of patronage of child welfare services (Demilew, 2017). There is a positive correlation between increased maternal education and patronage of child welfare programmes. This is supported by a study conducted in Nigeria by Okafor et al, (2014) where the study findings showed a positive effect on patronization of 
child monitoring programmes in relation to mothers' level of education. In a related study in Ghana by Adokiya et al. (2017). mothers/caregivers aged 40-49 years, being married, ethnic groups, Christian and female child have a higher likelihood of being fully immunized.

In Ghana, an essential part of the healthcare system is the establishment of Child Welfare Clinics all over the country (GHS, 2017)- under the community health planning and services (CHPS) initiative. Children under five years are assessed at Child Welfare Clinics for various child welfare and health services. Among the child health activities at the Child Welfare Clinics are growth monitoring, immunization against childhood killer diseases, vitamin A supplementation, treatment of minor ailments, referral of complicated illnesses, health talks and counselling of caregivers (Ministry of Health, 2015). The underfive clinic also combines preventive, treatment, health surveillance and education into a system of comprehensive health care. (Ministry of Health, 2014; Centre for Community Child Health, 2015). Caregivers of children are encouraged to attend CWC after delivery to benefit from Primary Health Care services including child immunizations and Growth Monitoring and Promotion (GMP)-commonly termed 'weighing'. However, about $70 \%$ of districts and regions have challenges with effective coverage of childhood immunization and a majority of children under-5 do not fully receive components of the child welfare services including immunization and growth monitoring (Bonsu, Senaya, Yawson, \& Eleeza, 2017). A study conducted in Techiman to evaluate the immunization coverage among children older than 12 months revealed that, about $80 \%$ of children between 12-23 months were immunized, however, it was revealed that most of these children were partially immunized and a small number of children were not immunized at all (Adokiya et al., 2017).Patronage of child welfare clinic services including immunization of children and regular growth monitoring of children in Ghana has remained low (Nyaku, Wardle, Ametewee, Bonsu, \& Opare, 2017). Statistics from the Ghana Health Service shows a consistent decline in the Child Welfare Clinic attendance and this decline has been attributed to knowledge gaps among caregivers, and a lack of defaulter tracing systems in most child welfare clinics (GHS, 2014). While this remain a national reason for the decline or limited utilization of CWC services, this study assessed those specific factors in rural communities that influence the utilization of CWC services.

\section{Methodology}

\section{Study Design}

A descriptive cross-sectional design was used as data was collected from participants only once and no further follow up of participants was done.

\section{Setting and population}

The study was conducted in Ho West District of Ghana which is one of the twenty- five (25) districts in the Volta Region with a land area of $1,002.79$ square kilometers. The total population of the district is 94,600 comprising of 45,361 males and 49,239 . The Total Fertility Rate for the District is 3.6 with a General Fertility Rate of 104.6 births per 1000 women aged 15-49 years which is higher than the regions rate of 99.2. The Crude Birth Rate (CBR) is 24.2 per 1000 population. The crude death rate for the District is 12.5 
per 1000 . The indigenes form $70 \%$ of the population while the remaining $30 \%$ are migrants. The district has six administrative sub districts with Abutia been one of them. The Abutia community is largely a sparsely populated community with many of its inhabitants been farmers and petty trading. Majority of children in this community are in school. Children who are not in school are engaged in helping their caretakers/parents with menial jobs in the farm or market.

The research population comprised caregivers of children aged eighteen to fifty-nine months residing in Abutia and its environs in the Ho-West district. The estimated population of children between 18 to 59 months in the community was estimated by the district health directorate to be 1348 (GHS, 2017).

\section{Sample and sampling technique}

The systematic sampling method was used to select 310 caregivers of children less than 60 months in the catchment area of the Abutia kloe sub district. The sample size was arrived at using: $n=N /\left(1+N\left(e^{2}\right)\right.$ (Mugenda, 1999) Where: $\mathrm{n}=$ sample size, $\mathrm{N}=$ study population size, $\mathrm{e}=$ sampling error (at $95 \%$ confidence level, the sampling error is 0.05$)$. Therefore, this implies that the sample size is:

$n=1348 /\left(1+1348 * 0.05^{2}\right)=308.5$

\section{Data collection and analysis}

Research assistants computed a sample fraction of 4 and based on which research study respondents were recruited. Research assistants in each community were dispatched in all directions to ensure total coverage of the communities. Study participants were recruited from homes, farms and sometimes in market stalls. It took an average of about 10 minutes to complete each research questionnaire. Respondents who could not read and write were assisted by the researchers to complete the questionnaire. Items in the questionnaire were both closed-ended and open-ended. Information on sociodemographic indices of the respondents, knowledge on the purpose of growth chart and child welfare services, availability and coverage of child welfare services were collected.

The data was entered into a Microsoft Excel Spreadsheet and cleaned and subsequently exported to statistical package for social sciences (SPSS version 22.0) for analysis. Data was analysed into simple descriptive statistics and test of associations. a p-value of less than 0.05 was considered as statistically significant at a $95 \%$ confidence interval.

\section{Ethics Clearance}

Ethical approval obtained from the Research and Ethics Committee of the University of Health and Allied Health Sciences - Institute of Health Research (UHAS.REC/A.5[24]17-18). Upon approval from the Ethics Review Board, permission was sort from Abutia Kloe community leaders and Health Service Administrators to interview clients. Informed consent was also sought from mothers before they voluntarily participated in the study. The respondents were informed of their right to participate or withdraw from the study without any repercussions. 


\section{Results}

The sample for this study were 310 mothers, as $58.4 \%$ were aged between $21-30$ years, $36.1 \%$ were 31 40 years, those aged less than 20 years and more than 40 years were $2.6 \%$ and $2.9 \%$ respectively. Also, $87.1 \%$ were unemployed, $10.3 \%$ employed and $2.6 \%$ students. Respondents have had formal education (82\%) at least up to the primary school level as $17.6 \%$ never had formal education (Table 1 ).

Table 1

Demographic characteristics of study respondents

\begin{tabular}{|llll|}
\hline & Parameter & Frequency(f) & Percent (\%) \\
\hline Age distribution & $<20$ & 8 & 2.6 \\
\hline $21-30$ & 181 & 58.4 \\
\hline Distribution of education status & None & 45 & 36.1 \\
\cline { 2 - 4 } & Basic & 112 & 2.9 \\
\cline { 2 - 4 } & Secondary & 44 & 14.5 \\
\cline { 2 - 4 } & Tertiary & 40 & 58.4 \\
\hline Employment status & Employed & 32 & 14.2 \\
\hline & Unemployed & 270 & 12.9 \\
\hline & Student & 8 & 87.1 \\
\hline
\end{tabular}

In Table 2 respondents indicated that their children have not received all the services corresponding to their ages (44.2\%), as $2.6 \%$ could not tell whether their babies had received all the appropriate services for their age while $53.2 \%$ received all CWC services corresponding to their ages. The main reason for default were completion of the major immunization $(72.3 \%)$ with a percentage stating their children starting school (25\%)and poor attitude of nurses (3.2\%).

Respondents had a fair knowledge on the available services at the child welfare clinic. These services included weighing of babies (23.32\%), vaccination (22.63\%), Vitamin A Supplementation $(20.55 \%)$ Health Education (15.63\%) and Counselling (17.63\%). Nonetheless, a good proportion of the mothers $(27.1 \%)$ did not know what declining weight record of their children meant. The meaning of weight decline by caregivers however were stated as child has lost weight (28.7\%), the child is sick (23.0\%) or child not eating well (21.2\%). 
Table 2

Maternal knowledge on Child Welfare Services

\begin{tabular}{|llll|}
\hline variables & Responses & Frequency & $\begin{array}{l}\text { Percentage } \\
\text { (\%) }\end{array}$ \\
\hline $\begin{array}{l}\text { Perceptions of services provided } \\
\text { at CWC }\end{array}$ & Weighing & 302 & 23.32 \\
\cline { 2 - 4 } & Vaccination & 294 & 22.63 \\
\cline { 2 - 4 } & Vitamin A Supplementation & 267 & 20.55 \\
\cline { 2 - 4 } & Health Education & 203 & 15.63 \\
\cline { 2 - 4 } $\begin{array}{l}\text { Meaning of declining weight } \\
\text { record }\end{array}$ & Counseling & 229 & 17.63 \\
& $\begin{array}{l}\text { Child Is Not Growing Well/Has lost } \\
\text { weight }\end{array}$ & 145 & 28.71 \\
\cline { 2 - 4 } & Child may be sick/Has been sick & 116 & 22.97 \\
\cline { 2 - 4 } & Child is not eating well & 107 & 21.19 \\
\cline { 2 - 4 } & Don't Know & 137 & 27.13 \\
\hline
\end{tabular}

\section{Relationship of demographic characteristics and CWC attendance}

The cross tabulation on level of education and regular CWC attendance showed a strong association with a chi-square test having a degree of freedom of 3 and a P-value less than 0.05 . Responses showed that $80 \%$ of none educated compared to $93.4 \%$ of educated persons where more likely to send their child for child welfare care services $\left(d f=3, r^{2}=8.071, p=0.03\right)$. Cross tabulation on marital status and CWC attendance showed an association. With a degree of freedom of 2 and a Chi-square which yielded a PValue of 0.00 . The results showed that married caregivers (85.2\%) as compared with unmarried ones $(60.5 \%)$ are more likely to seek child welfare services $\left(r^{2}=17.307, d f=2, p=0.000\right)$.Cross tabulation on respondents' number of children and regular attendance of CWC showed no association with a degree of freedom of 3 and a P-value of 0.244 . The relationship between the number of children and regular attendance of CWC is presented in Table 3. 
Table 3

Demographic characteristics and CWC attendance

\begin{tabular}{|c|c|c|c|c|c|c|c|}
\hline & \multicolumn{3}{|c|}{ Cross tabulations } & \multicolumn{4}{|c|}{ Pearson chi square correlation } \\
\hline & & Yes & No & & Value & Df & $P$ \\
\hline \multirow{4}{*}{$\begin{array}{l}\text { Level of education and } \\
\text { CWC attendance }\end{array}$} & None & 36 & 9 & $\mathrm{R}^{2}$ & $8.071^{a}$ & 3 & .045 \\
\hline & Basic & 146 & 35 & Likelihood Ratio & 13.658 & 3 & .003 \\
\hline & Secondary & 34 & 10 & $\begin{array}{l}\text { Linear-by-Linear } \\
\text { Assoc. }\end{array}$ & 3.508 & 1 & .061 \\
\hline & Tertiary & 32 & 0 & $\mathrm{~N}$ of Valid Cases & 302 & & \\
\hline \multirow{3}{*}{$\begin{array}{l}\text { Number of children and } \\
\text { CWC attendance }\end{array}$} & Married & 213 & 37 & $\mathrm{R}^{2}$ & $17.307^{a}$ & 2 & .000 \\
\hline & $\begin{array}{l}\text { Not } \\
\text { Married }\end{array}$ & 26 & 17 & Likelihood Ratio & 16.302 & 2 & .000 \\
\hline & Separated & 9 & 0 & $\begin{array}{l}\text { Linear-by-Linear } \\
\text { Assoc. }\end{array}$ & 1.266 & 1 & .261 \\
\hline \multirow{4}{*}{$\begin{array}{l}\text { Marital status and CWC } \\
\text { attendance }\end{array}$} & Married & 213 & 37 & $\mathrm{R}^{2}$ & $17.307^{a}$ & 2 & .000 \\
\hline & $\begin{array}{l}\text { Not } \\
\text { Married }\end{array}$ & 26 & 17 & Likelihood Ratio & 16.302 & 2 & .000 \\
\hline & Separated & 9 & 0 & $\begin{array}{l}\text { Linear-by-Linear } \\
\text { Association }\end{array}$ & 1.266 & 1 & .261 \\
\hline & Total & 248 & 54 & $\mathrm{~N}$ of Valid Cases & 302 & & \\
\hline
\end{tabular}

\section{Discussion}

The level of child welfare clinic coverage among children under-five years in a rural community in Ghana was assessed and it was shown that $44.2 \%$ of the respondents had not received all the CWC services appropriate for their ages. The World Health Organization (WHO, 2006) guideline makes it clear that every child should continue and complete the Growth Monitoring at the age of 59 months to get the maximum benefit to ensure the child's survival. Abutia Kloe located in the Ho West District is one of the $70 \%$ districts in Ghana where the majority of children under-five years do not fully receive components of the child welfare services including immunization and growth monitoring (Bonsu et al., 2017).

The default rate for CWC services was shown to be $72.3 \%$ which is higher than the recommended default rate of CWC services expected by the Ghana health service. The reasons espoused for CWC default included completion of immunization schedule (10.2\%). Other studies in Sub Saharan Africa showed that mothers consider only immunization services to be the sole reason for the provision of CWC services and upon its completion quits (Ghassemi 1986; Mapatano et al., 1997). Some mothers in the current study 
indicated that monthly weighing is not important as they could not identify any immediate tangible benefits associated with the service. It is therefore prudent that mothers have continuous education on the importance of growth monitoring as a crucial component of CWC. Also, another reason for default was because children start school earlier than the expected period for completion of the CWC services. CWC services are provided in primary health care institutions that largely provide services during working/ schooling hours. The nature of work of caregivers and having limited time (31.3\%) was cited as the reason for default for CWC services. Adu-Gyamfi \& Adjei (2013) reported that in Ghana this very reason was only second to completion of immunization as a reason for default (Adu-gyamfi \& Adjei, 2013). In this study, the mothers' preoccupation could be attributed to the fact that most mothers worked in their farms. This assertion is supported by another study in Ghana where the nurses mentioned that mothers fail to turn up because they are always busy in their farms (Adu-gyamfi \& Adjei, 2013).

Studies in Southern Ghana and Ethiopia made a similar finding where infants who attended primary school could not complete all aspects of CWS (Adu-gyamfi \& Adjei, 2013). In line with this finding, integrating CWS in early childhood school will go a long way in reducing the incidence of defaulting. When mothers lack information about CWS schedules, it affects coverage. Some mothers in the current study did not know that CWS lasts for 5 years, and might, therefore stop when the child is healthy and is not due for any of the specialized CWS. Studies conducted in Ghana, central Pakistan, Ethiopia and India confirms that patronage is affected when mothers lack information (Adu-gyamfi \& Adjei, 2013; Bilal, 2018; Etana \& Deressa, 2012; Phukan, Barman, \& Mahanta, 2008). Zewdie, Letebo, \& Mekonnen (2016) findings from their study captured the lack of information about vaccination schedules and service arrangements, including unusual circumstances such as what to do after missed appointment resulted in default. Few mothers (3.2\%) cited poor staff attitude as a reason for defaulting CWC. In Kenya, mothers especially those with malnourished children complained of such bad attitude toward them (Ettyang, Kielman, \& Maritim, 1993), and in Ethiopia mothers reported fear of mistreatment and lack of cooperation from service providers (Zewdie et al., 2016). In the Ga West Municipality of Ghana, an unprofessional attitude of staff hindered service utilization (Agbozo, Colecraft, Jahn, \& Guetterman, 2018).

The study established mothers' knowledge on services provided for children at the clinic to include: weighing $(23.32 \%)$, vaccination $(22.63 \%)$, vitamin A supplementation $(20.55 \%)$, health education $(15.63 \%)$ and counselling (17.63\%). This showed that the majority of mothers have had apt knowledge on the type of services at the CWC. In Ghana a significant portion (84\%) of respondents were able to mention at least three services provided to children at CWC (Adu-gyamfi \& Adjei, 2013). With regards to the purpose of growth chart and its interpretation, $32 \%$ of the mothers did not know the purpose of growth chart as $47.1 \%$, could not properly interpret the meaning of the growth chart. The growth chart is designed graphically for mothers to be able to interpret the results thus, mothers could serve as co monitors of the progress attained by their children. This is significant because mothers who know the health benefits of growth monitoring and understands the information displayed on the child health card are more likely to practice continued growth monitoring (Nyabuti, 2015). It is therefore necessary that health education on growth chart be intensified to increase participation to achieve the Ghana Health 
Service expectation that every child completes the CWC at aged 59 months in order to get the maximum benefit to ensure the child's survival (Ghana Health Service, 2007).

Distance plays a significant role in the utilization of healthcare. Although majority (86.5\%) of the respondents in the current study reached CWS centres in less than 30 minutes, $20.6 \%$ of the respondents cited that distance hinders full participation in CWS. In Ghana, the community- based health planning and services (CHPS) has helped provided primary health care services to had to reach communities and reduced significantly the distance covered in other to access primary health care services. Other studies have shown that mothers who walk over a long distance are more likely to default from services. In Ghana and Togo children whose parents had to walk half an hour to one hour to reach a healthcare centres were $57 \%$ more likely to have an incomplete coverage than those whose parents had to walk less than half an hour (Adu-gyamfi \& Adjei, 2013; Ekouevi et al., 2018). In Kenya for example, the availability of health facilities within $5 \mathrm{~km}$ return journey influenced the practice of continued growth monitoring (Nyabuti, 2015). Most (83.9\%) of the mothers who sort CWC services got to the health facility walking. Drop out increased in families with low income whereas the likelihood of incomplete growth monitoring decreased with increase in household's income (Ekouevi et al., 2018; Sheikh, Sultana, Ali, \& Akram, n.d.; Feleke, Adole, \& Bezabih, 2017). Health care providers must be stationed closer to the target communities to reduce the likelihood of spending additional money on transport in seeking services within these particular communities.

The study also revealed that the higher the educational level of the mother, the more likely it is for the mother to participate in CWS $\left(r^{2}=8.071, p=0.03\right)$. Educated mothers are more likely to read and comprehend the child health record book and as a result, will participate positively to the attainment of good health outcomes. The finding of this study supports other similar studies that reported that educated mothers were less likely to default as compared to mothers with no or only basic education in Ghana, Togo, Ethiopia, Nigeria, Senegal, Bangladesh and India (Adu-gyamfi \& Adjei, 2013; Ekouevi et al., 2018; Access, 2016; Odusanya, Alufohai, Meurice, \& Ahonkhai, 2008; Abdou et al., 2017; Sheikh, Sultana, Ali, \& Akram, n.d;Phukan et al., 2008). These findings imply that female literacy is vital in increasing CWS patronage and to increase participation among mothers attending CWS. Mothers were more likely not to default CWS if they were married, indicating that the involvement of the father might play a decisive role in increasing CWS coverage $(r 2=17.307, d f=2, p=0.000)$. This finding agrees with a study in Ghana and Kenyan where marriage had the potential of enhancing attendance of continued CWS, husbands when provided with health education appear to be willing to assist and encourage their wives to take their children for child welfare services at the health facilities (Adokiya et al. 2017; Nyabuti, 2015, Zewdie et al., 2016). In light of this finding, it is necessary to investigate the educational level of husbands when assessing regular participation in CWS. This is prudent because Asirifi (2009) says that low levels of formal education influences health care delivery in Ghana.

\section{Conclusion}


Majority of mothers of the Abutia Kloe Municipality do not understand the information displayed on the Growth chart. Health care implementers should focus on educating mothers and caregivers on how to read and interpret the growth monitoring charts using the colour codes displayed in the book. Policy makers should look at intensifying education on the need to continue growth monitoring up to 59 months because mothers are likely to default on completion of immunization. Ways to integrate growth monitoring with schools should be looked at in order to ensure continued growth monitoring.

\section{Declarations}

\section{Ethics approval and consent to participate}

Ethical approval obtained from the Research and Ethics Committee of the University of Health and Allied Health Sciences - Institute of Health Research (UHAS.REC/A.5[24]17-18). Upon approval from the Ethics Review Board, permission was sort from Abutia Kloe community leaders and Health Service Administrators to interview clients. Informed consent was also sought from mothers before they voluntarily participated in the study. The respondents were informed of their right to participate or withdraw from the study without any repercussions.

\section{Consent for publication}

Not applicable

\section{Availability of data and materials}

All data generated or analysed during this study are included in this published article and no data set is deposited in any data repository.

\section{Competing interests}

The authors declare that they have no competing interests

\section{Funding}

All funding from the conception and writing of this manuscript is from the researchers' personal resources and no external sources of funding were used. 
Authors' contributions

All authors have contributed substantially to the conception, collection of data and drafting of this manuscript

\section{References}

Adokiya, M. N., Baguune, B., \& Ndago, J. A. (2017). Evaluation of immunization coverage and its associated factors among children 12-23 months of age in Techiman Municipality, Ghana, 2016. Archives of Public Health, 75(1), 28.

Agbozo, F., Colecraft, E., Jahn, A., \& Guetterman, T. (2018). Understanding why child welfare clinic attendance and growth of children in the nutrition surveillance programme is below target: lessons learnt from a mixed methods study in Ghana. BMC nursing, 17(1), 25.

Asirifi, Y. (2009). Child health: past, present and future Challengesi. Ghana medical journal, 43(2).

Bilal, M., Mazhar, S., \& Ali, M. R. (2018). ASSESMENT OF EXPANDED PROGRAM ON IMMUNIZATION COVERAGE IN CHILDREN LESS THAN TWO YEARS COMING TO PAEDS OUTPATIENT DEPARTMENT SERVICES HOSPITAL LAHORE. INDO AMERICAN JOURNAL OF PHARMACEUTICAL SCIENCES, 5(5), 41654177.

Bilal, S. M., Moser, A., Blanco, R., Spigt, M., \& Dinant, G. J. (2014). Practices and challenges of growth monitoring and promotion in Ethiopia: a qualitative study. Journal of health, population, and nutrition, 32(3), 441.

Daniel, B., Tesfaye, N., Mekonin, E., Kassa, A., Mensur, K., \& Zerihun, E. (2017). Knowledge and Attitude on Growth Monitoring and its Associated Factors among Mothers/Guardians of Children Less than Two Years in Areka Town, Southern Ethiopia, 2017. J Nutr Disorders Ther, 7(216), 2161-0509.

Demilew, Y. M. (2017). Factors associated with mothers' knowledge on infant and young child feeding recommendation in slum areas of Bahir Dar City, Ethiopia: cross sectional study. BMC research notes, 10(1), 191.

Ekouevi, D. K., Gbeasor-Komlanvi, F. A., Yaya, I., Zida-Compaore, W. I., Boko, A., Sewu, E., ... \& Landoh, D. E. (2018). Incomplete immunization among children aged 12-23 months in Togo: a multilevel analysis of individual and contextual factors. BMC public health, 18(1), 952.

Emmanuel, N. K., Gladys, E. N., \& Cosmas, U. U. (2013). Consumer knowledge and availability of maternal and child health services: a challenge for achieving MDG 4 and 5 in Southeast Nigeria. BMC health services research, 13(1), 53.

Emmanuel, N. K., Gladys, E. N., \& Cosmas, U. U. (2013). Consumer knowledge and availability of maternal and child health services: a challenge for achieving MDG 4 and 5 in Southeast Nigeria. BMC health 
services research, 13(1), 53.

Etana, B., \& Deressa, W. (2012). Factors associated with complete immunization coverage in children aged 12-23 months in Ambo Woreda, Central Ethiopia. BMC public health, 12(1), 566.

Ettyang, G. A., Kielmann, A. A., \& Maritim, G. K. (1993). Growth monitoring in rural Kenya: experiences from a pilot project. In Growth Promotion for Child Development: proceedings of a colloquium held in Nyeri, Kenya, 12-13 May 1992. IDRC, Ottawa, ON, CA.

Feleke, F. W., Adole, A. A., \& Bezabih, A. M. (2017). Utilization of growth monitoring and promotion services and associated factors among under two years of age children in Southern Ethiopia, 1-9. https://doi.org/10.6084/m9.figshare.4725601

Ghana Statistical Service. (2015). Demographic and Health Survey.

GHS. (2017). Newborn Care Programme.

Gyamfi, A. B. A., \& Adjei, B. (2013). Child Welfare Clinic Attendance among Children 24-59 Months in Assin North Municipality, Ghana. International Journal of Innovation Education and Research, 1(4), 59-68.

Hug, L., Ejdemyr, S., Idele, P., Hogan, D., \& Mathers, C. (2015). Global, regional, and national levels and trends in under-5 mortality between 1990 and 2015, with scenario-based projections to 2030: a systematic analysis by the UN Inter-agency Group for Child Mortality Estimation. The Lancet, 386(10010), 2275-2286. https://doi.org/10.1016/S0140-6736(15)00120-8

Kinney, M. V., Kerber, K. J., Black, R. E., Cohen, B., \& Nkrumah, F. (2010). Sub-Saharan Africa's mothers, newborns, and children: Where and why do they die? PLoS Medicine, 7(6).

https://doi.org/10.1371/journal.pmed.1000294

Mbengue, M. A. S., Sarr, M., Faye, A., Badiane, O., Camara, F. B. N., Mboup, S., \& Dieye, T. N. (2017). Determinants of complete immunization among senegalese children aged 12-23 months: evidence from the demographic and health survey. BMC public health, 17(1), 630.

Ministry Of Health. (2015). Under Five's Child Health Policy: 2007-2015, 2007-2015.

Negussie, A., Kassahun, W., Assegid, S., \& Hagan, A. K. (2016). Factors associated with incomplete childhood immunization in Arbegona district, southern Ethiopia: a case - control study, 1-9. https://doi.org/10.1186/s12889-015-2678-1

Nyaku, M., Wardle, M., Eng, J. V., Ametewee, L., Bonsu, G., Opare, J. K. L., \& Conklin, L. (2017). Immunization delivery in the second year of life in Ghana: the need for a multi-faceted approach. The Pan African medical journal, 27(Suppl 3). 
Odusanya, O. O., Alufohai, E. F., Meurice, F. P., \& Ahonkhai, V. I. (2008). Determinants of vaccination coverage in rural Nigeria. BMC Public health, 8(1), 381.

Okafor, I. P., Dolapo, D. C., Onigbogi, M. O., \& lloabuchi, I. G. (2014). Rural-urban disparities in maternal immunization knowledge and childhood health-seeking behavior in Nigeria: a mixed method study. African health sciences, 14(2), 339-347.

Phukan, K., Barman, M. P., \& Mahanta, J. (2008). Brief Report Factors Associated with Immunization Coverage of Children in Assam , India: Over the First Year of Life, (May), 249-252. https://doi.org/10.1093/tropej/fmn025

Saunders, M., Lewis, P., \& Thornhill, A. (2012). The Ultimate Guide to writing a Dessertation in business studies: a step by step approach. (6th ed.). Pearson Education Limited.

Service, G. H. (2007). Reproductive and Child Health/Family Planning.

Sheikh, N., Sultana, M., Ali, N., Akram, R., Mahumud, R., Asaduzzaman, M., \& Sarker, A. (2018). Coverage, Timelines, and Determinants of Incomplete Immunization in Bangladesh. Tropical medicine and infectious disease, 3(3), 72.

UNICEF. (2016). Child Health and Community Health Systems.

United Nations. (2017). Sustainable Development Goals.

WHO. (2011). WHO I Equity and child-survival strategies. Bulletin of the World Health Organisation.

Yawson, A. E., Bonsu, G., Senaya, L. K., Yawson, A. O., Eleeza, J. B., Awoonor-Williams, J. K., ... \& Agongo, E. E. A. (2017). Regional disparities in immunization services in Ghana through a bottleneck analysis approach: implications for sustaining national gains in immunization. Archives of Public Health, 75(1), 10.

Zewdie, Asamnew, Mekitew Letebo, and Tinsae Mekonnen. "Reasons for defaulting from childhood immunization program: a qualitative study from Hadiya zone, Southern Ethiopia." BMC public health 16.1 (2016): 1240. 